Brit. J. vener. Dis. (1964), 40, 90.

\title{
IMPLICATIONS OF THE REPORTED FINDING OF TREPONEMES OF LITTLE OR NO VIRULENCE AFTER THE TREATMENT OF SYPHILIS WITH PENICILLIN*
}

\author{
BY \\ R. R. WILLCOX \\ St. Mary's Hospital, London
}

The need for renewal of interest in treponematoses research has been pointed out from various sources in the last decade. Attention has repeatedly been drawn to the need for long-term studies on the survival and infectivity of treponemes in the body and their position in latency and other stages of infection, and in sero-reactive treated cases. This aspect was particularly emphasized by the Expert Committee on Venereal Infections and Treponematoses of the World Health Organization (1960) in its study of the best means of intensifying and coordinating future research. The fresh approach by Collart, Borel, and Durel in Paris to the problems concerned is therefore welcomed.

Members of the Medical Society for the Study of Venereal Diseases, London, were recently fortunate to obtain at first hand from Drs Collart and Durel the results of their research. Their findings had been presented at an earlier stage to the World Forum on Syphilis and Treponematoses in Washington D.C. in 1962 and some members had been privileged to hear a preliminary report when the Society met in Paris in 1961.

\section{The Findings}

The appearance of preliminary information in WHO research documents (Collart, Borel, and Durel, 1962a, b) and recent publications (Collart, Borel, and Durel, 1962c, d, e, f, 1963a, b) have raised much interest.

After much repetitive, laborious, and painstaking work, micro-organisms resembling $T$. pallidum have been found and photographed in small numbers in stained sections of the lymph nodes of syphilitic rabbits 8 to 12 months after treatment with large doses of penicillin, the original infections having been left for approximately 2 years before treatment.

Moreover, similar organisms were demonstrated

* Received for publication December 24, 1963 in the cerebrospinal fluid of rabbits, clinical lesions were reactivated by steroid administration in the ears of two of twelve rabbits, and treponemes were recovered from the nares of five.

Further investigations were undertaken in ten human patients with treated late syphilis (mostly cases of tabes dorsalis). All but one had received repeated courses of penicillin, and of arsenic and bismuth over periods of 1 to 16 years. The treponemal immobilization (TPI) reaction was positive in all of them. Similar organisms were found (and photographed) in the lymph nodes of all cases.

The organisms both in rabbits and in man apparently showed little or no virulence. In one rabbit, into which scrotal transplantation of a lymph node had been made, a nodule remained in which treponemes could be recovered by aspiration for 42 days-although this may represent survival rather than true infection-and a positive treponemal immobilization reaction developed in this rabbit only. In the remainder, however, passage was not obtained, but neither was passage readily achieved after this long interval in untreated control rabbits.

The French workers believe the organisms to be $T$. pallidum and hence that penicillin is not usually able to eradicate the treponeme completely in cases of late syphilis in rabbits, and possibly in man when the organism remains to some extent trapped and protected in the lymph nodes. In such cases host and parasite have achieved a mutual adjustment, but that this balance can be upset is shown by the development of lesions in rabbits when given steroids. Conventional serum tests for syphilis using lipid antigens are negative, but the continued existence of the organisms is considered to be indicated by a positive treponemal immobilization reaction. The situation is likened to that sometimes encountered in tuberculosis, in which a few bacilli, extremely difficult to demonstrate, may persist for long periods with a normal sedimentation rate in clinically inactive cases. 
Startling as these findings are, they should be seen in relation to our previous different concepts of the course-and particularly of the criteria for the cure-of syphilis. Latent infections with treponemata, including $T$. pallidum, $T$. pertenue, and $T$. cuniculi, with organisms recoverable from the lymph nodes, are found in many animals, particularly the mouse and rat, and frequently the guinea-pig and hamster. These infections are accompanied by negative serum reactions to tests with lipid antigens. The treponemal immobilization reaction in mice, however, may be positive (Gastinel, Collart, Hamelin, Vaisman, and Dunoyer, 1958) or-if negative-a positive TPI reaction may be subsequently induced in subinoculated rabbits (Berlinghoff, 1957).

Virulence of $T$. pallidum has been demonstrated in such rodents by inoculation into rabbits with the subsequent development of lesions, but treponemes are extremely difficult to demonstrate in proved infective material (see WHO, 1961). However, although $T$. pallidum has been shown to remain virulent in the mouse for 2 to 3 years (Rosahn, 1952), and virulence in the rabbit is readily maintained for decades by repeated passage into fresh animals, insufficient information is available concerning the prolonged persistence of virulence in the same animal. It may be that man and mouse have something in common after all!

\section{Immediate Research Needs}

The present paper considers some of the implications of the new findings, particularly in relation to the research needs, both urgent and long-term, which are in consequence created.

There are three immediate requirements: (1) confirmation of the presence of these organisms; (2) their identification with $T$. pallidum: (3) the correlation of their presence with the treponemal immobilization reaction.

(1) Need for Confirmation.-As with all original observations confirmation in a different laboratory is the first essential. As time will be required for some of the few laboratories equipped for such work to collect the animals fulfilling the requirements of the study, a start may be made on human material, i.e. on lymph nodes from treated late syphilitics. Such material is not easy to obtain and is only procurable on an individual basis.

(2) Need for Identification with T. pallidum.-The organisms concerned, although morphologically resembling $T$. pallidum, may of course be some other treponeme. For example, the rabbits used might have

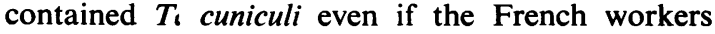
justifiably claim there was no evidence whatever of pallidoidosis in their stock. This could not, however, explain the treponemes found in man as human beings are said to be unaffected by this organism (Levaditi, Marie, and Nicolau, 1921 ; see also Turner and Hollander, 1957; WHO, 1961). Nevertheless, it is not beyond the bounds of possibility that the organisms could be septicaemic saprophytic treponemes (with some low cross-antigenic powers) derived from the mouth or elsewhere. It is necessary, therefore, after confirmation of their presence in syphilitic humans has been obtained, to show that they are not also found in control patients not suffering from syphilis.

Many hours of concentrated toil are required to locate the organisms in one specimen when they are present. The search for them in controls, when they are anticipated to be absent, requires even more patience. On the other hand, whereas lymph node material from treated human syphilitics is hard to come by, the procurement of control material offers no great problem as it should be readily obtainable from surgical and post mortem sources.

The necessity for the final identification of these organisms with $T$. pallidum, although obvious, is difficult to satisfy. The possibilities of immunofluorescence immediately spring to mind, although many hours will be required to find the organisms, and this may limit the satisfactory use of this method at the present time. Hope for the future lies in an improvement of the techniques of immunofluorescence and in the evolution of more rapid microscopical methods of finding the organisms. The latter possibility is considered later.

Cultural techniques should also be tried. If the organisms are saprophytic treponemes it should be possible to cultivate them. If they are $T$. pallida which have lost their virulence, one might still be able to cultivate them and their isolation in vitro would add force to the theory that the cultured strains (Reiter, Kazan, Noguchi, and others), claimed originally to have been derived from syphilitic material, were in fact originally strains of $T$. pallidum. Successful culture would enable the morphology to be studied under the electron microscope, besides permitting serological, antigenic, and other studies with ample material.

(3) Need for the Correlation of the Presence of the Organisms with the TPI Reaction.-The French workers believe that the presence of the organisms is indicated by a positive TPI test. It does not necessarily follow that this is the case; if the organisms are avirulent $T$. pallida, there is no logical reason, at the present stage of our inadequate knowledge, why they should not also be present in persons with a negative TPI test. However, to establish such a 
correlation would assist enormously in demonstrating, measuring, and understanding the new problems which arise if these organisms are confirmed as $T$. pallida: it would in consequence, enormously reduce the amount of subsequent research required. Indeed the mind boggles at the hiatus in knowledge which would result if the organisms were confirmed and if no such correlation were established.

Three groups of patients suggest themselves on whom future work could most profitably be concentrated:

(1) Patients apparently satisfactorily treated for secondary syphilis, 30 per cent. of whom still have a persistent positive TPI reaction, the significance of which is unknown (Perdrup, 1960). The finding of the organisms in TPI-positive persons, and not in those with negative reactions or in controls, would establish the new theories at their base of origin.

(2) The "problem" group of syphilis patients in which active clinical lesions are found which do not respond to systemic anti-syphilitic therapy (e.g. patients with interstitial keratitis, nerve deafness, and possibly those with optic atrophy and tabetic lightning pains). Could the presence of the organisms be responsible for these conditions?

(3) Immigrants residing in temperate climates who have both reagin and immobilizing sero-reactivity from past yaws infections. Such persons only very seldom develop clinical lesions and at first thought it would appear unlikely for live $T$. pertenue still to be harboured within them. If this were shown to be the case, however, the implications concerning syphilis would be extended to the other treponematoses also.

It has been considered that reagin is derived as an auto-antibody response from the slimy layer of the treponeme provided by the host as a protection against virulent treponemes, and that the formation of immobilizing antibody results when the organisms die and their uncovered surfaces are exposed (Christiansen, 1963). If this is the case, the organisms, being largely avirulent, would provoke no slimy layer (and therefore no reagin formation), but some must be dying in sufficient numbers to result in a positive TPI reaction. Implied therefore is that, in late syphilis, some treponemes must be emerging from their protected lairs to be killed by the host.

Implications of the Findings, if confirmed in Late and Latent Syphilitics who are TPI Reactors and have been treated with Penicillin Alone

If the organisms are confirmed as $T$. pallida, the implications are profound. They may be considered in relation to $(a)$ basic research needs; $(b)$ concepts of cure; (c) follow-up requirements.

\section{(a) Basic Research Needs}

(i) A great impetus will be given to fundamental syphilis research which to date has been undertaken by dedicated workers in only a very few laboratories in the world. Money will be required in large quantities for buildings, equipment, and personnel. However, the reason for it, i.e. the persistence of the wily treponeme in the human host for years on end and in cases of late latent syphilis even after what has been regarded as completely adequate modern treatment, is likely to appeal forcibly to the popular mind and the necessary funds will doubtless be forthcoming if properly sought. This and other relevant aspects have already been pointed out by the World Health Organization in its approach to more co-ordinated treponematoses research (WHO, 1961).

(ii) More research is necessary concerning the natural course of syphilis in animals, in addition to man-not only the rat, mouse, guinea-pig, hamster, and rabbit, but larger animals also like the dog, sheep, and cow in whom latent infections with treponemes have occasionally been reported (see WHO, 1961). Particularly should this research be concerned with the persistence of virulence and effects of treatment.

(iii) Improved, faster methods of microscopy will have to be evolved if rapid results are to be obtained. The immediate work involving confirmation and examination of non-syphilitic controls can be undertaken at one or two centres at present concerned with treponemal research, but extra trained workers, obtained with WHO or other assistance, are indicated for the long hours of microscopy required for each specimen. The next stage of the work aimed at identification with $T$. pallidum, which involves the examination of lymph nodes from syphilitic patients, requires a coordinated international co-operative effort with a number of associated laboratories in different countries equipped and manned for a task which has so many potential ramifications.

The microscope engineers should be invited to help in designing equipment for long-term use in this project. The provision of a power-moved stage for the microscope (with a brake control and photographic attachment), which would divide each slide into a set number of fields and move from field to field after an appropriate number of seconds, recording each field numerically as it does so for future reference, would be the first step. Possibly 
this already exists. The exact location of suspicious organisms could then be rapidly noted without delaying the examination of the remainder of the slide when found. A numerical check would also be provided on the number of fields examined in both control and test material and the total time spent on them could be accurately compared.

Once this has been achieved, it should be possible to project the microscopic image on to a screen, and to provide a remote-control focusing attachment, a brake, and a button control for micro-photography. This would allow the worker to sit in armchair comfort in a darkened room. If the stage was improved to hold a number of slides, which automatically replaced those which have already been examined, the work could proceed day and night on a shift basis if desired.

Even further automation might be made possible by devising an electronic instrument based in principle on a television scanner, which would automatically photograph any field (recording its numerical position also) containing objects of a predetermined length, breadth, and optical density. Provided the instrument could be adjusted not to record too many artefacts it would be able to operate without human assistance by night and provide relatively few photographs for more detailed human examination in the morning.

\section{(b) Concepts of "Cure" in Syphilis}

(i) The impact of the work of Collart and his colleagues on the concepts of biological cure in syphilis are summarized in the Table. This refers solely to biological cure and not to clinical cure, and applies only to patients who have had adequate treatment and in whom the results of cerebrospinal fluid and other relevant examinations are normal. Even the "cured" cases in the second group would be in doubt were it shown that the organisms concerned could still be present with a negative TPI reaction.

TABLE

IMPACT ON CONCEPTS OF BIOLOGICAL CURE AFTER ADEQUATE TREATMENT

\begin{tabular}{c|c|c|c}
\hline $\begin{array}{c}\text { Concept of } \\
\text { Cure }\end{array}$ & Reagin Test & TPI Test & Outcome \\
\hline \multirow{4}{*}{ Old } & $\begin{array}{l}\text { Negative } \\
\text { Positive }\end{array}$ & $\begin{array}{c}\text { Negative } \\
\text { Negative }\end{array}$ & $\begin{array}{c}\text { Cure } \\
\text { Cure } \\
\text { (false-positive) }\end{array}$ \\
\hline New & $\begin{array}{l}\text { Negative } \\
\text { Positive }\end{array}$ & $\begin{array}{l}\text { Positive } \\
\text { Positive }\end{array}$ & $\begin{array}{c}\text { Probable cure } \\
\text { Probable cure }\end{array}$ \\
\hline $\begin{array}{l}\text { Negative } \\
\text { Positive }\end{array}$ & $\begin{array}{l}\text { Negative } \\
\text { Negative }\end{array}$ & $\begin{array}{c}\text { Cure } \\
\text { Cure } \\
\text { (false-positive) }\end{array}$ \\
\hline & $\begin{array}{l}\text { Negative } \\
\text { Positive }\end{array}$ & $\begin{array}{l}\text { Positive } \\
\text { Positive }\end{array}$ & $\begin{array}{c}\text { No cure } \\
\text { No cure }\end{array}$ \\
\hline
\end{tabular}

To date, the clinical results of treating syphilis with penicillin have been so satisfactory-and, let it be stated, these results are still no less good if these persistent organisms are proved to be $T$. pallidathat isolated reports of possible non-success have tended to be discounted and some other explanation sought. But a number of failures has been reported through the years. Barnett, Epstein, Brewer, Koch, and Beirne (1954) noted that the penicillin treatment of late syphilis did not always prevent progression, as also did Reynolds (1948) in cases of treated late syphilis. Individual cases of treatment resistance have been reported (e.g. by Thiers and Fayolle, 1963, and Rajam and Rangiah, 1955) and possible cases of gummatous syphilis with negative reactions to reagin tests but reactive to the TPI test have also been noted (Le Coulant, Texier, and Maleville, 1962).

In the past, if dubious activity has been found(e.g. in an aorta post mortem) in a much-treated person-this activity has not always been accepted. The pathologist has often been challenged to demonstrate a treponeme which he has usually been unable to do. Now the French workers are finding treponemes!

(ii) "Resistance" to Penicillin.-The organisms under discussion have been demonstrated in man after massive doses of arsenicals and penicillin have been given. They are therefore resistant to one or both of these drugs, or protected from them, or not reached by them. It has often been stated that $T$. pallidum, unlike the gonococcus, shows no sign of becorning resistant to penicillin. Certainly, in the treatment of early syphilis, the results continue to show a high level of success. Nevertheless, it is also true that, as virulent $T$. pallidum cannot be cultivated in vitro, it is not possible to conduct sensitivity tests which would show the finer changes of developing resistance. Indeed, Schamberg (1963) has queried whether the present resurgence of syphilis is not at least partly due to this phenomenon. He pointed out that the only laboratory data of the effect of penicillin in syphilis relate to CD50 doses in animals which were obtained in the early days of penicillin, which investigations have not been repeated, and he called for their repetition without delay.

(iii) Effects of Steroids.-The French workers reactivated lesions in their treated rabbits by the use of steroids. Turner and Hollander (1950) noted that, under the influence of cortisone, treponemes multiplied though the host response was lessened; Gastinel, Collart, Vaisman, Hamelin, and Dunoyer (1960) also indicated that, in untreated syphilitic rabbits, steroids might produce a dissemination of lesions. Can the same happen in man, even in penicillin-treated cases? 
This raises the whole question of the use of steroids in persons with late syphilis. Possibly they may be harmful. Equally possible is that they should be used deliberately with antibiotic cover in cases of late latent and late syphilis to enable penicillin to reach the treponemes more easily.

Certainly, sero-reversal in so-called sero-fast syphilis has been reported after the use of penicillin and cortisone (Ochiuleț 1960). Clinical research, using penicillin with steroids to determine whether more cases show post-treatment changes in the TPI findings than when penicillin alone has been used would appear to be indicated.

\section{(c) Follow-up of Syphilis}

The practice in some clinics of never discharging cases of late syphilis would seem to receive added justification until this new situation is clarified.

It would also seem prudent to prolong the followup after the treatment of early syphilis, at least in those patients with persistent reactivity to the TPI test, until the significance of this is known. Certainly the need is to increase the post-treatment observation of syphilis, not to decrease it as has been recently suggested in some quarters.

Inevitably the French findings, even if taken no further, will also result in a greatly increased demand for the treponemal immobilization test in the management of all forms of treated syphilis and increased facilities for this test are likely to be required.

\section{Summary and Conclusions}

(1) The reported findings by Collart and his colleagues of treponemes, resembling $T$. pallidum but of little or no virulence, in the lymph nodes of both man and animals with long-standing syphilis after large doses of penicillin (in animals) and of penicillin and arsenicals (in man) are reviewed and their implications are discussed.

(2) The need for independent confirmation of this work and for the identification of these organisms with, or their distinction from, $T$. pallidum, is stressed. The latter would require systematic examination of lymph nodes from non-syphilitic controls and would be facilitated by improved methods of immunofluorescence and by cultural means.

(3) The French workers believe that the presence of the treponemes is indicated by sero-reactivity to the treponemal immobilization test. If the organisms are confirmed as being $T$. pallida this also requires urgent investigation, for should it be shown to be true the problem could at least be measured and the amount of subsequent research required would be materially reduced. Three groups are suggested as the most promising material for testing:

(i) Patients with treated secondary syphilis, both TPI-positive and TPI-negative;

(ii) Patients with clinical lesions which have always been of a "problem" nature (i.e. those with interstitial keratitis, nerve deafness, optic atrophy, and with lightning pains);

(iii) TPI-positive patients with sero-positivity from past yaws, endemic syphilis, or pinta.

(4) The implications regarding research needs are discussed. The findings will inevitably lead to increased fundamental research in syphilis and more knowledge is required concerning the persistence and virulence of treponemes in animals, particularly in those in which latent infections are known to be common. To confirm the present work and to provide its logical immediate extension, more trained workers should be specifically assigned to the task. International co-operation (through WHO) is required between the centres concerned, and new technical methods (some of which are suggested in principle) are required to speed the microscopical work if the necessary information is to be obtained quickly.

(5) The implications regarding the concepts of cure of syphilis are outlined and the possible effects of steroids in late cases considered. The need to increase the length of follow-up in treated early syphilis until the significance of persistent immobilizing activity is known, and not to discharge cases of treated late syphilis (so that adequate material is available for clinical and laboratory study) are stressed. There is thus likely to be an immediate demand for increased facilities for the treponemal immobilization test in cases of treated late syphilis.

(6) The clinical results obtained in the penicillin treatment of syphilis are not altered by the discovery of Collart and his colleagues. The attitude to the disease, and to its diagnosis, course, and treatment would, however, be profoundly shaken were the findings confirmed. 


\section{REFERENCES}

Barnett, C. W., Epstein, N. N., Brewer, A. F., Koch, R. A., and Beirne, G. A. (1954). A.M.A. Arch. Derm. Syph., 69, 91 .

Berlinghoff, W. (1957). Derm. Wschr., 136, 929.

Christiansen, S. (1963). Lancet, 1, 423.

Collart, P., Borel, L.-J., and Durel, P. (1962a). Ann. Inst. Pasteur, 102, 596.

,-- , and - (1962b). Ibid., 102, 693.

,-- , and $-(1962 \mathrm{c})$. Ibid., 103, 953.

,$- \frac{1}{89}$, and - (1962d). Ann. Derm. Syph. (Paris), 89, 488 . $-\frac{8,}{153}$, and - (1963a). Proph. sanit. morale, 35,

$\overline{\text { Gastinel, }}, \overline{\mathbf{P}}$, and $-(1963 \mathrm{~b})$. Ibid., 35, 114 Dunoyer, F. (1958). Ann. Derm. Syph. (Paris), 85, 497.

- $\frac{}{(1960)}$ Vaisman, A., Hamelin, A., and Dunoyer, F. (1960). Ibid., 87, 612 .

Le Coulant, P., Texier, L., and Maleville, J. (1962). Bull. Soc. franc. Derm. Syph. P, 69, 99.

Levaditi, C., Marie, A., and Nicolau, S. (1921). C. $R$. Acad. Sci. (Paris), 172, 1542.

Ochiuleț, I. (1960). Derm.-Vener. (Buc.), 5, 545.

Perdrup, A. (1960). Acta derm.-venereol. (Stockh.), 40, 340.

Rajam, R. V., and Rangiah, P. N. (1955). Brit. J. vener. Dis., 31, 25.

Reynolds, F. W. (1948). Amer. J. Svph., 32, 233.

Rosahn, P. D. (1952). A.M.A. Arch. Derm. Syph., 66, 547.

Schamberg, I. L. (1963). Brit. J. vener. Dis., 39, 87.

Thiers, H., and Fayolle, J. (1962). J. Méd. Lyon, 43, 1957.

Turner, T. B., and Hollander, D. H. (1950). Bull. Johns Hopk. Hosp., 87, 505.

__ and (1957). "Biology of the Treponematoses". WHO monograph Ser. No. 35, Geneva.

World Health Organization (1961). "T. pallidum". WHO research document WHO/VDT/RES/8.

Importance des tréponèmes peu virulents observés chez des syphilitiques jadis traités par la pénicilline

\section{RÉSUMÉ}

(1) L'auteur discute l'observation du Dr. Collart et de ses collègues sur les tréponèmes (formes spiralées), semblables au $T$. pallidum mais peu virulents, trouvés dans les frottis de ganglions chez l'homme et chez les animaux de laboratoire après traitement par la pénicilline.

(2) Il souligne le besoin de confirmer cette observation et d'identifier ces formes spiralées avec le Tp ou de les en distinguer. Ce dernier exige l'examen des ganglions de témoins non-syphilitiques, chose qui demande de moyens plus exacts de culture et d'immunofluorescence.

(3) Collart et coll. constatent que la réaction du sérum au test TPI indique la présence du tréponème. Il faut identifier ces organismes pour mesurer l'étendue du problème et éviter un travail futur prolongé. Trois groupes de personnes seront nécessaires à cette étude:

- les malades atteints de syphilis secondaire, avec TPI positif ou négatif

- les malades dont les lésions ont toujours posé un problème (kératite interstitielle, surdité nerveuse, atrophie optique, tabes avec douleurs fulgurantes)

- les malades avec TPI négatif mais reaction positive due au pian, à la syphilis éndemique, ou à la pinta.

(4) On discute le coût de ces recherches. Ces observations exigent que l'on intensifie les recherches sur la syphilis et les tréponèmes qui persistent chez les animaux où l'infection latente est fréquente. Il faut y mettre plusieurs expérientés. On a besoin de la coopération internationale (de l'OMS) entre les laboratoires, et de nouvelles techniques pour expédier la microscopie.

(5) Il est nécessaire d'établir des critères absolus de la guérison de la syphilis et des effets des steroïdes sur la syphilis latente. Il faut suivre les cas traités de syphilis précoce afin que l'importance de la persistence de la réactivité immobilisante soit connue. Il faut retenir à l'hôpital les cas de syphilis latente non-traités comme réservoir de matériaux pour les études de clinique et de laboratoire. Ou demandera immédiatement que soient augmentées les facilités de pratiquer le test d'immobilisation du tréponème dans les cas de syphilis tardive traités.

(6) Les résultats obtenus par le traitement de la syphilis avec la pénicilline ne sont pas changés par la découverte de Collart et coll., mais notre opinion de cette maladie, de son diagnostic, et de son traitement serait profondément boulversée si ces observations pouvaient être confirmées. 